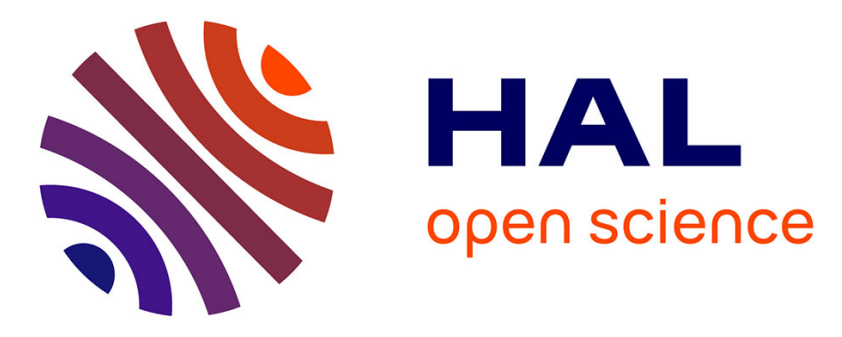

\title{
Synthesis of conducting transparent few-layer graphene directly on glass at $450{ }^{\circ} \mathrm{C}$
}

Chang Seok Lee, Costel Sorin Cojocaru, Waleed Moujahid, Bérengère Lebental, Marc Chaigneau, Marc Châtelet, François Le Normand, Jean-Luc Maurice

\section{To cite this version:}

Chang Seok Lee, Costel Sorin Cojocaru, Waleed Moujahid, Bérengère Lebental, Marc Chaigneau, et al. Synthesis of conducting transparent few-layer graphene directly on glass at $450{ }^{\circ} \mathrm{C}$. Nanotechnology, 2012, 23, pp.5603. 10.1088/0957-4484/23/26/265603 . hal-00753309

\section{HAL Id: hal-00753309 \\ https://hal-polytechnique.archives-ouvertes.fr/hal-00753309}

Submitted on 19 Nov 2012

HAL is a multi-disciplinary open access archive for the deposit and dissemination of scientific research documents, whether they are published or not. The documents may come from teaching and research institutions in France or abroad, or from public or private research centers.
L'archive ouverte pluridisciplinaire HAL, est destinée au dépôt et à la diffusion de documents scientifiques de niveau recherche, publiés ou non, émanant des établissements d'enseignement et de recherche français ou étrangers, des laboratoires publics ou privés. 


\title{
Synthesis of conducting transparent few-layer graphene directly on glass at $450{ }^{\circ} \mathrm{C}$
}

\author{
Chang Seok Lee, ${ }^{1}$ Costel Sorin Cojocaru, ${ }^{1, \text { a) }}$ Waleed Moujahid, ${ }^{1,2}$ Bérengère Lebental, ${ }^{1,2}$ \\ Marc Chaigneau, ${ }^{1}$ Marc Châtelet, ${ }^{1}{ }^{\text {François Le Normand }}{ }^{1,3}$ and Jean-Luc Maurice ${ }^{1, b)}$ \\ 1) LPICM (Laboratoire de Physique des Interfaces et des Couches Minces) UMR 7647, \\ CNRS-Ecole polytechnique, 91128 Palaiseau Cedex, France \\ 2) Université Paris-Est, Ifsttar, 58 boulevard Lefebvre, 75732 Paris Cedex 15, France \\ 3) InESS (Institut d'Electronique du Solide et des Systèmes) UMR 7163, Université de \\ Strasbourg-CNRS, 23, rue du Loess, BP 20 CR, 67037 Strasbourg Cedex 2, France \\ E-mail: a) costel-sorin.cojocaru@polytechnique.edu. \\ b) jean-luc.maurice@polytechnique.edu.
}

\begin{abstract}
Post-growth transfer and high growth temperature are two major hurdles that research has to overcome to get graphene out of research laboratories. Here, using a plasma-enhanced chemical vapour deposition process, we demonstrate the large-area formation of continuous transparent graphene layers at temperatures as low as $450{ }^{\circ} \mathrm{C}$. Our few-layer graphene grows at the interface between a pre-deposited 200-nm Ni catalytic film and an insulating glass substrate. After nickel etching, we are able to measure the optical transmittance of the layers without any transfer. We also measure their sheet resistance directly and after ink-jet printing of electrical contacts: sheet resistance is locally as low as $500 \Omega / \mathrm{sq}$. Finally the samples equipped with printed contacts appear to be efficient humidity sensors.
\end{abstract}

PACS: 68.65.Pq Graphene films, 81.05.ue Materials science of graphene, 07.07.Df Sensors

\section{Introduction}

The integration of graphene in microelectronics requires the ability to synthesize this material in a reproducible and low cost manner. Early preparation methods, such as mechanical or chemical exfoliation of HOPG (highly ordered pyrolytic graphite) [1,2], or epitaxial growth by high temperature annealing of (0001) $\mathrm{SiC}$ [3] in ultra-high vacuum (UHV), fall short in terms of reproducibility or scalability.

In contrast, methods involving the catalytic crystallization of graphene on a metallic substrate may enable large-area fabrication and appear well adapted to meet the requirements for industrial applications. Carbon atoms can be brought to the metal substrate by several techniques. The most popular is $(i)$ chemical vapour deposition (CVD) [4-6], which uses gaseous (methane, acetylene, etc.) or liquid (ethanol, propanol, etc.) carbon sources [7,8]. Interestingly, CVD may be induced by a laser, enabling direct growth of a graphene pattern [9]. Besides CVD, carbon atoms can also be brought by (ii) a solid-state source (organic layers, amorphous carbon, diamond, etc.) [10-14] or (iii) they can be implanted in the metallic substrate [15-17]. In all these methods, graphene is obtained during a high-temperature stage or during the sample cooling immediately following it. It often includes several graphene layers ("few-layer graphene, FLG"). However, the substrate in these techniques is a conducting metal, such as nickel or copper. Thus, after the graphene film is formed, its subsequent use in electrical devices generally requires transfer to an insulating, functional substrate. This transfer operation introduces a variety of defects into the graphene sheet [18].

Several teams around the world have attempted to develop alternative growth methods to avoid transfer. For instance, one can evaporate the thin metal substrate, after graphene growth, by a long hightemperature treatment [19]. Graphene sheets can also be obtained by directly depositing carbon or a 
carbon-based layer on $\mathrm{SiO}_{2}$ before depositing nickel atop and by finally anneal to transform the carbon into graphene [20, 21]. They can even be obtained directly on $\mathrm{SiO}_{2}$ without the help of a catalyst layer [22]. However, the main drawback of all these transfer-free techniques is the requirement for a high temperature step before deposition [19], during deposition [20, 22] or during annealing [21].

This high temperature requirement is not only costly, but also incompatible with IC processes or with low melting-temperature substrates such as glass. Thus a variety of trials have attempted to grow graphene in a low temperature range $\left(300-550^{\circ} \mathrm{C}\right)$, particularly without catalyst [23-25].

The main character of the present study is to obtain crystallisation of graphene at low temperature, directly on glass, with the help of a metallic catalyst. Our specific approach provokes the growth of graphene at the interface between a catalytic film and an insulating substrate [26, 27].

In this paper, we demonstrate the synthesis of continuous large-area graphene layers directly on glass substrates at temperatures as low as $450{ }^{\circ} \mathrm{C}$. These films are made of 1 to $\sim 30$ layers (few-layer graphene, FLG). We then use such films in the fabrication of low-cost humidity sensors. The latter are obtained by ink-jet printing electrical contacts on the as-grown samples after nickel etching. Such sensors have a variety of applications in civil and urban engineering, such as the assessment of building energy performances or the monitoring of transport infrastructure ageing [28].

\section{Growth method}

We initially discussed the possibility of interfacial growth in a patent [26]. We were then able to demonstrate the principle using dc-PECVD [27, 29]. At an atomic scale, the catalytic crystallisation that takes place here is similar to the one which is well documented on PECVD of carbon nanotubes [30-33].

Such a growth at the $\mathrm{Ni} / \mathrm{SiO}_{2}$ interface has then also been demonstrated by other groups using standard CVD or various solid-state carbon sources [21,34]. The difference of the dc-PECVD process discussed here with standard thermal CVD is that here, carbon species have a higher kinetic energy (several hundreds of eV) and thus disturb the top Ni surface, which probably plays a significant role in promoting interface segregation and precipitation.

Moreover, the particular configuration of our setup (triode mode) enables us to extract energetic ionic carbon and hydrogen species and to aim them at the substrate along the electric field lines, which are perpendicular to the substrate surface [35]. From the existing literature on the bias-enhanced nucleation of diamond [36, 37], we believe that above a threshold kinetic energy (around some tens of eV), a subplantation of carbon atoms takes place below the catalyst surface. The exact mechanisms are presently under investigation.

Here, a 200-nm Ni film is first evaporated on a 1-mm thick glass substrate. The substrate is loaded on the cathode of our triode type direct-current PECVD system. We apply a hydrogen plasma in order to reduce the oxidized top metal surface. We then apply the dc-PECVD process for either 6 or $12 \mathrm{mn}$ to the substrate heated at $450{ }^{\circ} \mathrm{C}$. The dc voltage applied between anode and central electrode is $650 \mathrm{~V}$; an additional few tens of volts are applied between the latter and cathode. We use a flow of methane (40 $\mathrm{sccm})$ and hydrogen $(50 \mathrm{sccm})$. To observe and use the graphene layers that have precipitated at the nickel-glass interface, we first remove in situ the graphitic carbon that has grown on the nickel top surface with a water vapour plasma. We then etch off the nickel layer in a commercial solution at room temperature (Nickel Etchant TBF - Transene). Figure 1 depicts the main steps of this fabrication process.

Before etching the nickel, we check by Raman spectrometry (figure 2a), scanning electron microscopy (SEM) (figures $2 \mathrm{~b}$ and $2 \mathrm{c}$ ) and XPS that no trace of carbon remains on the nickel top surface (Raman spectra were recorded using a LabRAM-HR800 from Horiba-Jobin-Yvon, and the scanning electron 
microscope was a Hitachi S-4800 FE). Hence, we know that after Ni etching, only interface graphene remains on the glass substrate: the films that we study and use in the following are solely made of the graphene layers that have grown directly on the glass surface below the Ni layer.

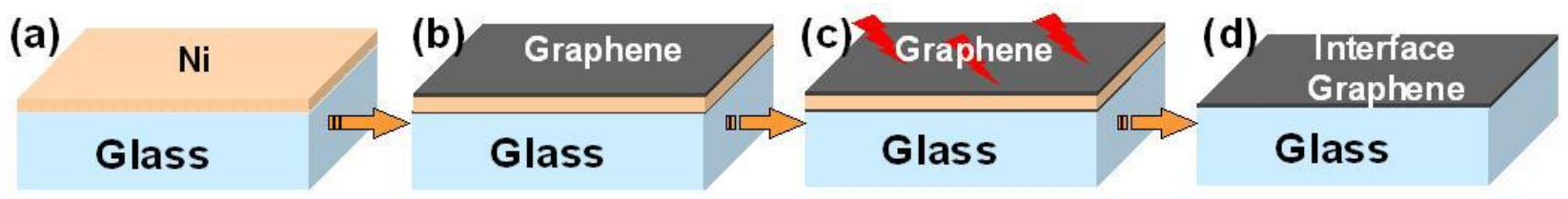

Figure 1. Schematic of interfacial graphene growth: (a) Ni evaporation on glass, (b) dc-PECVD at $450{ }^{\circ} \mathrm{C}$, (c) etching of the surface graphene by $\mathrm{H}_{2} \mathrm{O}$ plasma, followed by wet $\mathrm{Ni}$ etching, (d) final graphene-onglass sample.
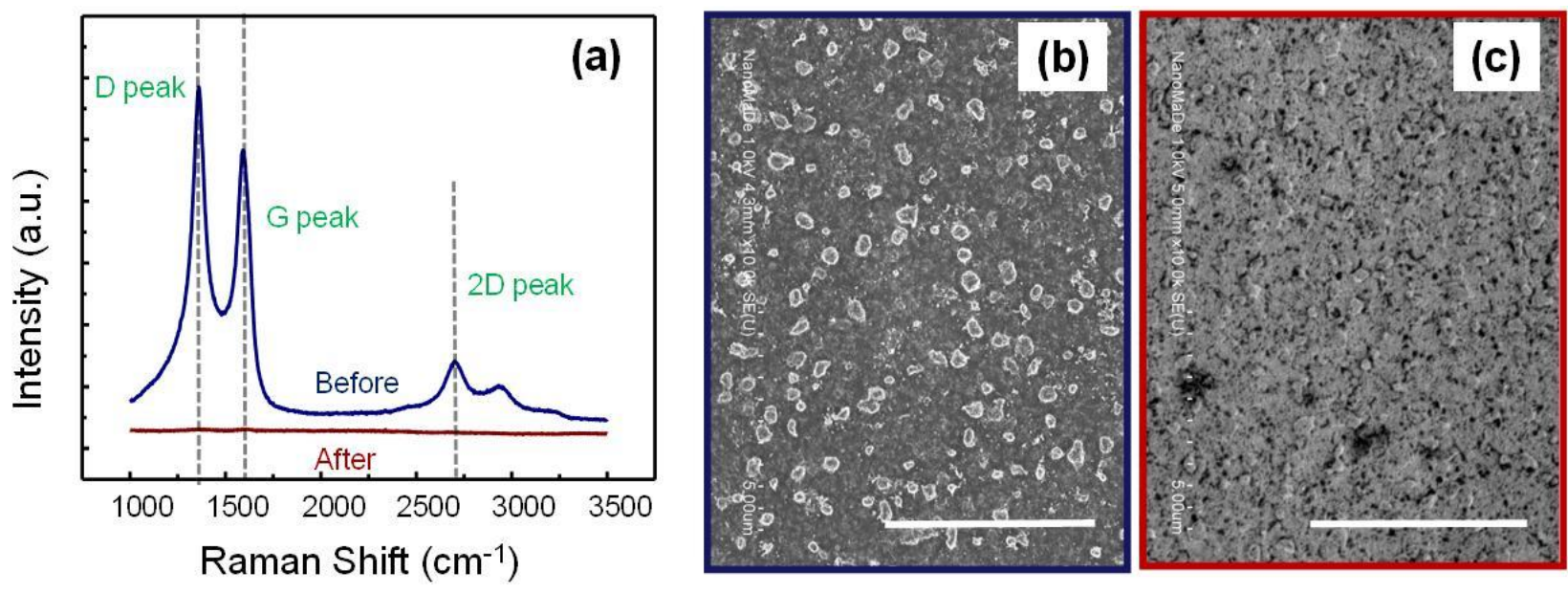

Figure 2. (a) Raman spectra of the top nickel surface after dc-PECVD process and before (in blue) or after (in red) water vapour plasma exposure. These spectra indicate that all trace of carbon has been removed from the top surface. (b, c) SEM images of the top Ni surface before (b) and after (c) plasma treatment (Scale bar is $5 \mu \mathrm{m}$ ).

\section{Characterization of the films}

Transmission electron microscopy (TEM, figure 3) was performed using a Jeol 2010 F equipped with a Gatan Imaging Filter for electron energy loss spectroscopy (EELS). Experiments were carried out at 200 $\mathrm{keV}$ on a film grown with the 12-mn process. The TEM sample was prepared by transferring onto a TEM grid a part of the film that was floating in the Ni-etchant. The film exhibits the same regular wavy contrast over the whole observable area (figures $3 \mathrm{a}$ and $3 \mathrm{~b}$ ). It appears to be made of regions of ca. $200 \mathrm{~nm}$ in diameter (figure $3 \mathrm{~d}$ ) bordered by bent areas where the number of graphene layers appears to be 10 to 30 (figures $3 \mathrm{e}$ and $3 \mathrm{~g}$ ). We expect that the flat areas are only about half as thick (figure $3 \mathrm{~g}$ ). The local bending of the flakes causes the thickness to vary with a $\sim 200-\mathrm{nm}$ characteristic distance. Such a wavelength remaining below the visible range, this roughness is not optically visible (see figure 4). EELS (figure $3 \mathrm{c}$ ) and electron diffraction (figure 3f) indicate that the film is crystalline. The shape of the EELS carbon K-edge exhibits features well-referenced in graphite (see for instance [38]), which correspond to the transition of the ejected core electrons to the $\pi *$ and $\sigma^{*}$ conduction bands. The powder pattern in figure $3 \mathrm{e}$ indicates that the structure is nanocrystalline: the line width of the 100 ring corresponds to a size of coherently diffracting areas ( grain size) of $\sim 3 \mathrm{~nm}$, according to Scherrer formula. 

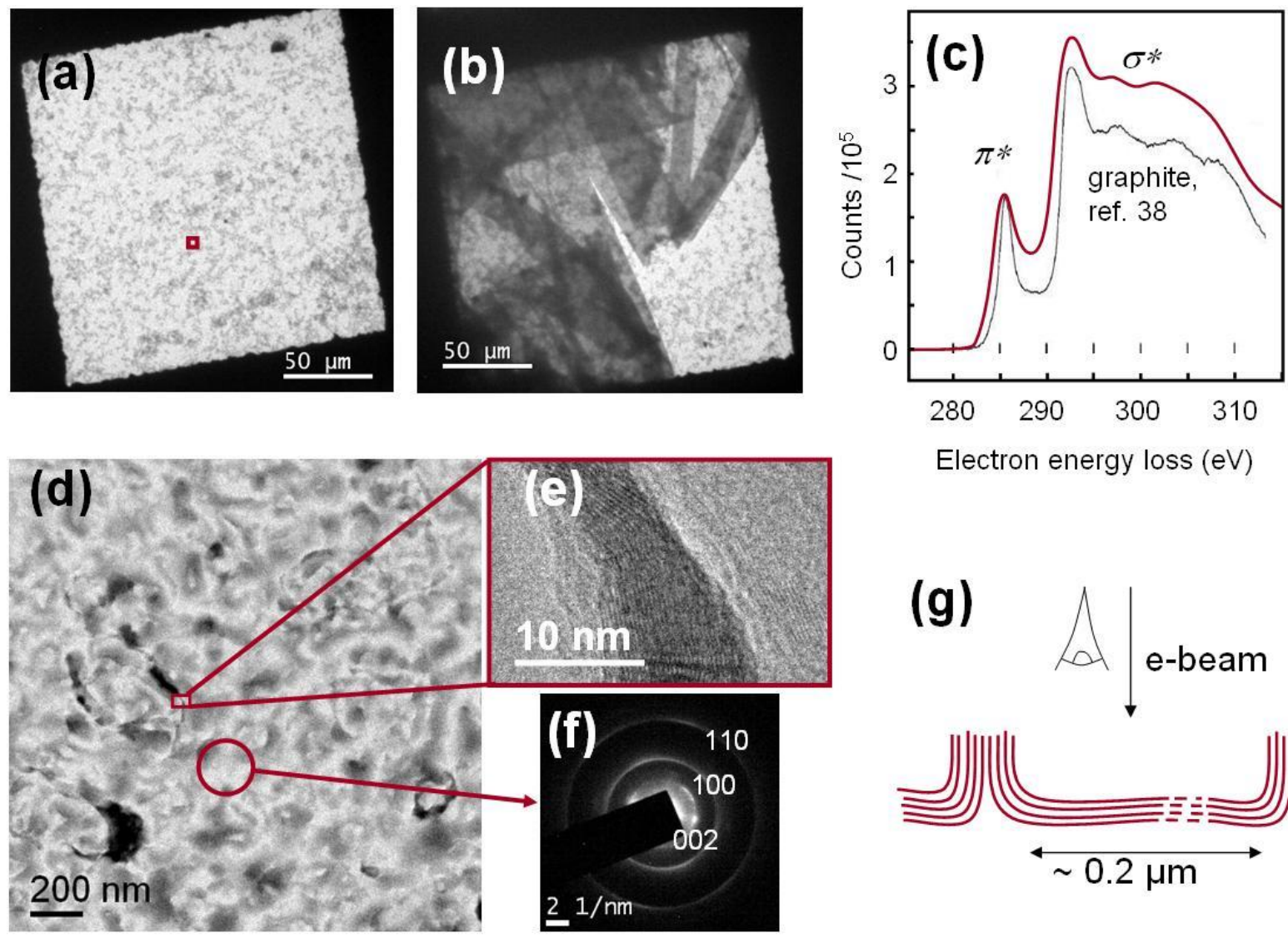

Electron energy loss (eV)

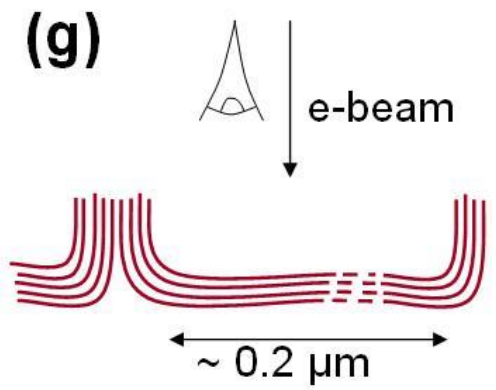

Figure 3. Plan-view TEM of a graphene film grown at $450^{\circ} \mathrm{C}$ by a $12-\mathrm{mn}$ dc-PECVD process. (a, b) Lowmagnification images with superimposed films in (b) due to folding; the small red square in (a) represents the area of (d). (c) Electron energy loss carbon K-edge, recorded in a homogeneous area such as that circled in (d) (in red) compared to a spectrum characteristic of graphite (in black, courtesy of O. Stéphan, copyright (1996) by The American Physical Society [38]). (d) Intermediate magnification and (e) highresolution images showing bent parts exhibiting stacks of graphene layers. (c) Electron diffraction pattern recorded over the area circled in (d). The 100 and 110 rings are characteristic of nanocrystalline graphene; the 002 dots come from bent parts such as that in (b). (g) Schematic of the layers deduced from the observations.

Combined optical and Raman observations (figure 4) confirm on a larger scale the TEM observations. Except for a fold that probably formed during the drying process, we observe (figure 4) that the FLG film covers uniformly the glass substrate. Figure $4 \mathrm{~b}$ exhibits a Raman spectrum typical of the layer, acquired over an area of $1 \mu \mathrm{m}^{2}$. The $\mathrm{G}$ band (figure $4 \mathrm{~b}$ ), originating from in-plane vibrations of $\mathrm{sp}^{2}$ carbon bonds, is observed at $1597 \mathrm{~cm}^{-1}$. The defect signal is relatively important ( $\mathrm{D}$ in figure $4 \mathrm{~b}, I_{D} / I_{G}=1.18$ ), while the $2 \mathrm{D}$ band remains weak $\left(I_{G} / I_{2 D}=3.54\right)$. The strength of the $\mathrm{D}$ band may be explained by the nanocrystalline nature of our material: there is a high density of defective bonds at the boundaries between the nano-grains. 

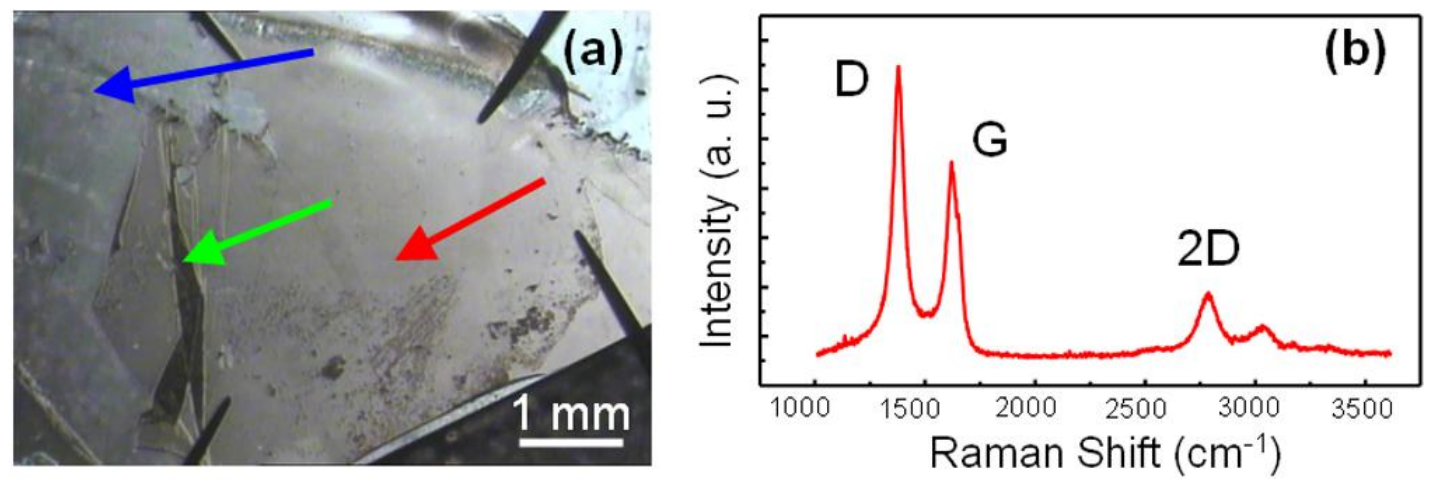

Figure 4. (a) Optical image of the interfacial FLG film shown in figure 3, after water plasma exposure and subsequent nickel etching. The red arrow indicates graphene, the blue one, glass, and the green one, a fold in the FLG film. (b) Raman spectrum typical of the film.

The optical transmittance of the FLG films measured in the visible and near infra-red range (figure 5) is found to be respectively $78.4 \%$ and $67.3 \%$ at $650 \mathrm{~nm}$ for plasma exposure times of 6 and 12 minutes. The dependence of the transmittance on wavelength remains small, which is very promising for future applications based on transparency given the relative simplicity of the process (low-temperature synthesis and transfer-free fabrication). Although the nanocrystalline structure of our material differs from that of true graphene, one may roughly estimate the number of layers by using the " $2.3 \%$ transmittance loss for each additional layer" rule [39]. Based on this relationship, the number of layers is respectively $\sim 9$ and $\sim 15$ for the 6-mn and 12-mn deposits. Thus the number of layers measured by TEM (figure $3 \mathrm{~b}$ ) would be characteristic of the bent parts only; the flat parts would be thinner.

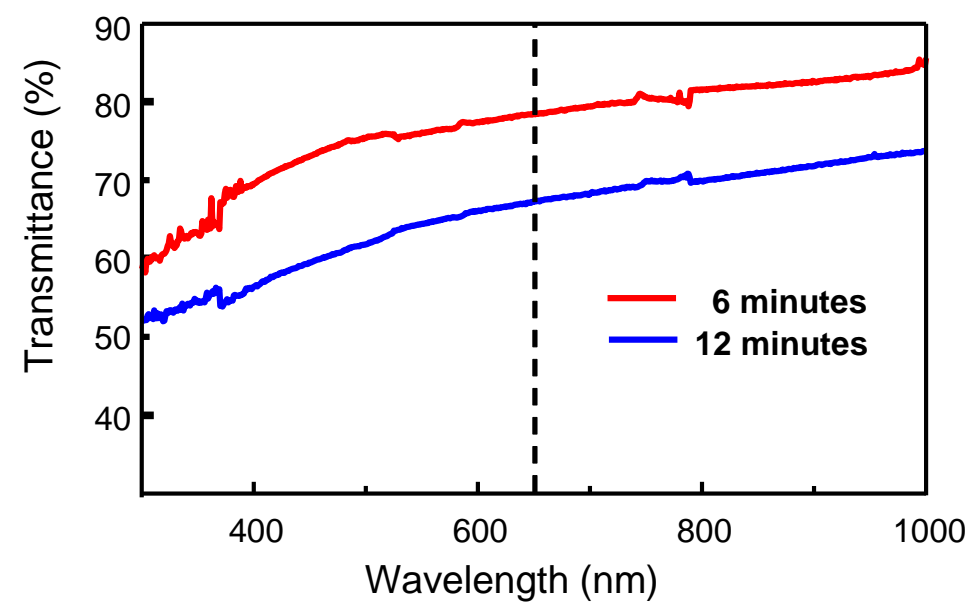

Figure 5. Optical transmittance in the 300 to 1000 -nm range, for two plasma exposure times. The vertical dotted line indicates the 650-nm wavelength (see text).

\section{Conductivity and sensor application}

As the graphite sheets are grown directly on an insulating substrate, they do not need to be transferred before measuring the sheet resistance. We directly ink-jet printed series of four $500 \mu \mathrm{m} \times 1000 \mu \mathrm{m}$ parallel rectangular electrodes separated by $500 \mu \mathrm{m}$ using INKTEC TEC-IJ-010 silver ink in a Dimatix DMP-2800 materials printer (figure 6a). 
We measured a sheet resistance as low as $500 \Omega / \mathrm{sq}$ on a 12-mn sample. Sheet resistances vary significantly depending on the location on the samples, which is attributed to inhomogeneous thickness. Quite interestingly, the sample exposed only 6 minutes to the growth plasma, which presents $78.4 \%$ transmittance at $650 \mathrm{~nm}$ (figure 5), exhibits an average sheet resistance of $5 \pm 1.2 \mathrm{k} \Omega / \mathrm{sq}$.

Sensitivity of materials to gas is often related to the density of defect sites [40], which makes a priori our material an outstanding candidate for gas sensing. We characterized two 12-mn sheets under increasing relative humidity (RH). For both devices, the sensitivity to humidity is clear, especially above $40 \% \mathrm{RH}$. For the best conductive material, the sheet resistance increases by almost $700 \Omega$ from 3.3 to $4.0 \mathrm{k} \Omega / \mathrm{sq}$. (+ $20 \%$ ) between $5 \%$ and $63 \%$ relative humidity (figure $6 \mathrm{~b}$ ); for the other sheet, the resistance increases by $3 \mathrm{k} \Omega$ from 45 to $48 \mathrm{k} \Omega / \mathrm{sq}$. (+7 \%) between $4 \%$ and $86 \% \mathrm{RH}$. These variations appear large enough to be measured by discrete electronic components, thus paving the way toward actual graphene-based integrated humidity sensors.
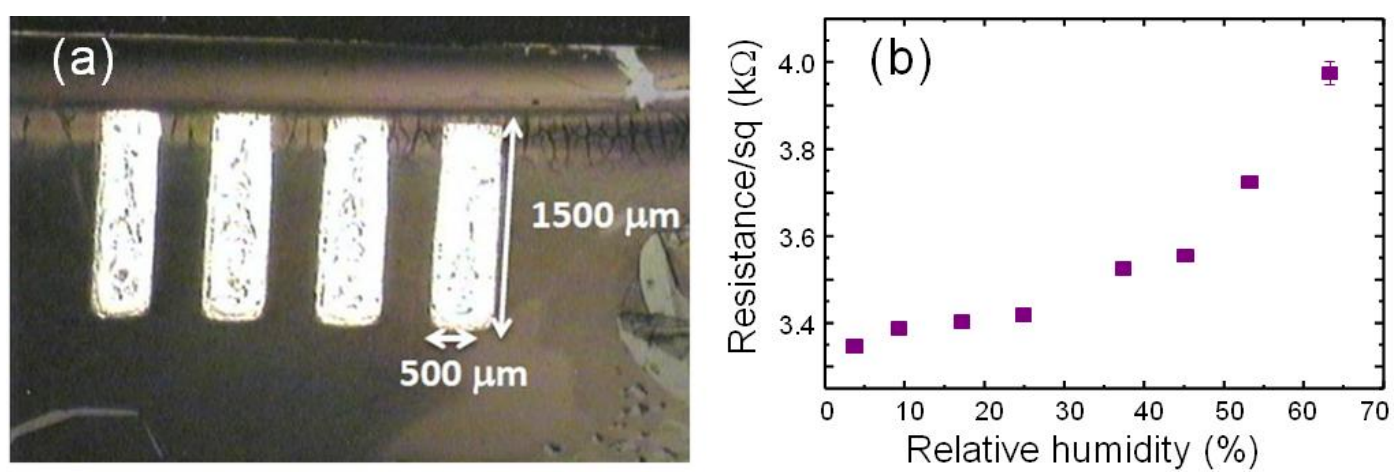

Figure 6. (a) The inkjet printed silver electrodes; (b) sheet resistance versus relative humidity for a graphene sheet resulting from the $12-\mathrm{mn}$ process.

\section{Conclusions}

To conclude, we have demonstrated the low temperature $\left(450{ }^{\circ} \mathrm{C}\right)$ growth of continuous few-layer graphene sheets on a low cost, insulating substrate: glass. No transfer is required before post-processing to fabricate electronic devices. The material features locally low sheet resistance, although the defect density is quite high. The defect density may explain the high sensitivity of our material to relative humidity. These results herald the prototyping of actual low-cost graphene sensors for civil and urban engineering applications.

\section{Acknowledgements}

JLM thanks G. Rizza and P.-E. Coulon at CIMEX, École polytechnique, France for the use of the Jeol 2010F.

\section{References}

[1] Novoselov K S, Geim A K, Morozov S V, Jiang D, Zhang Y, Dubonos S V, Grigorieva I V and Firsov A A 2004 Electric field effect in atomically thin carbon films Science 306 666-69

[2] Li X, Wang X, Zhang L, Lee S and Dai H 2008 Chemically derived, ultrasmooth graphene nanoribbon semiconductors Science 319 1229-32 
[3] Berger C, Song Z M, Li T B, Li X B, Ogbazghi A Y, Feng R, Dai Z T, Marchenkov A N, Conrad E H, First P N and de Heer W A 2004 Ultrathin epitaxial graphite: 2D electron gas properties and a route toward graphene-based nanoelectronics J. Phys. Chem. B 108 19912-16

[4] Reina A, Jia X T, Ho J, Nezich D, Son H B, Bulovic V, Dresselhaus M S and Kong J 2009 Large area, few-layer graphene films on arbitrary substrates by chemical vapor deposition Nano Lett. 9 30-35

[5] Li X S, Cai W W, An J H, Kim S, Nah J, Yang D X, Piner R, Velamakanni A, Jung I, Tutuc E, Banerjee S K, Colombo L and Ruoff R S 2009 Large-area synthesis of high-quality and uniform graphene films on copper foils Science 324 1312-14

[6] Bae S, Kim H, Lee Y, Xu X, Park J-S, Zheng Y, Balakrishnan J, Lei T, Ri Kim H, Song Y I, Kim Y-J, Kim K S, Ozyilmaz B, Ahn J-H, Hong B H and Iijima S 2010 Roll-to-roll production of 30inch graphene films for transparent electrodes Nat. Nanotechnol. 5 574-78

[7] Miyata Y, Kamon K, Ohashi K, Kitaura R, Yoshimura M and Shinohara H 2010 A simple alcohol-chemical vapor deposition synthesis of single-layer graphenes using flash cooling Appl. Phys. Lett. 96263105

[8] Guermoune A, Chari T, Popescu F, Sabri S S, Guillemette J, Skulason H S, Szkopek T and Siaj M 2011 Chemical vapor deposition synthesis of graphene on copper with methanol, ethanol, and propanol precursors Carbon 49 4204-10

[9] Park J B, Xiong W, Gao Y, Qian M, Xie Z Q, Mitchell M, Zhou Y S, Han G H, Jiang L and Lu Y F 2011 Fast growth of graphene patterns by laser direct writing Appl. Phys. Lett. 98123109

[10] Sun Z, Yan Z, Yao J, Beitler E, Zhu Y and Tour J M 2010 Growth of graphene from solid carbon sources Nature 468 549-52

[11] Zheng M, Takei K, Hsia B, Fang H, Zhang X, Ferralis N, Ko H, Chueh Y-L, Zhang Y, Maboudian R and Javey A 2010 Metal-catalyzed crystallization of amorphous carbon to graphene Appl. Phys. Lett. 96063110

[12] García J M, He R, Jiang M P, Kim P, Pfeiffer L N and Pinczuk A 2011 Multilayer graphene grown by precipitation upon cooling of nickel on diamond Carbon 49 1006-12

[13] Hofrichter J, Szafranek B u N, Otto M, Echtermeyer T J, Baus M, Majerus A, Geringer V, Ramsteiner M and Kurz H 2009 Synthesis of graphene on silicon dioxide by a solid carbon source Nano Lett. $1036-42$

[14] Rodríguez-Manzo J A, Pham-Huu C and Banhart F 2011 Graphene growth by a metal-catalyzed solid-state transformation of amorphous carbon ACS Nano 5 1529-34

[15] Garaj S, Hubbard W and Golovchenko J A 2010 Graphene synthesis by ion implantation Appl. Phys. Lett. 97183103

[16] Baraton L, He Z, Lee C S, Maurice J-L, Cojocaru C S, Gourgues-Lorenzon A-F, Lee Y H and Pribat D 2011 Synthesis of few-layers graphene by ion implantation of carbon in nickel thin films Nanotechnology 22085601

[17] Baraton L, He Z B, Lee C S, Cojocaru C S, Châtelet M, Maurice J L, Lee Y H and Pribat D 2011 On the mechanisms of precipitation of graphene on nickel thin films EPL (Europhysics Letters) 9646003

[18] Lin Y-M, Valdes-Garcia A, Han S-J, Farmer D B, Meric I, Sun Y, Wu Y, Dimitrakopoulos C, Grill A, Avouris P and Jenkins K A 2011 Wafer-scale graphene integrated circuit Science 332 1294-97

[19] Ismach A, Druzgalski C, Penwell S, Schwartzberg A, Zheng M, Javey A, Bokor J and Zhang Y 2010 Direct chemical vapor deposition of graphene on dielectric surfaces Nano Lett. 10 1542-48

[20] Lee C M and Choi J 2011 Direct growth of nanographene on glass and postdeposition size control Appl. Phys. Lett. 98183106

[21] Yan Z, Peng Z, Sun Z, Yao J, Zhu Y, Liu Z, Ajayan P M and Tour J M 2011 Growth of bilayer graphene on insulating substrates ACS Nano 5 8187-92 
[22] Chen J, Wen Y, Guo Y, Wu B, Huang L, Xue Y, Geng D, Wang D, Yu G and Liu Y 2011 Oxygen-aided synthesis of polycrystalline graphene on silicon dioxide substrates $\mathrm{J}$. Am. Chem. Soc. 133 17548-51

[23] Rümmeli M H, Bachmatiuk A, Scott A, Börnert F, Warner J H, Hoffman V, Lin J-H, Cuniberti G and Büchner B 2010 Direct low-temperature nanographene CVD synthesis over a dielectric insulator ACS Nano 4 4206-10

[24] Scott A, Dianat A, Borrnert F, Bachmatiuk A, Zhang S, Warner J H, Borowiak-Palen E, Knupfer M, Buchner B, Cuniberti G and Rummeli M H 2011 The catalytic potential of high-kappa dielectrics for graphene formation Appl. Phys. Lett. 98 073110-3

[25] Zhang L C, Shi Z W, Wang Y, Yang R, Shi D X and Zhang G Y 2011 Catalyst-free growth of nanographene films on various substrates Nano Res. 4 315-21

[26] Baraton L, Cojocaru C S and Pribat D 2008 Process for controlled growth of graphene films International patent 0805769-2008.

[27] Lee C S, Baraton L, He Z, Maurice J-L, Chaigneau M, Pribat D and Cojocaru C S 2010 Dual graphene films growth process based on plasma-assisted chemical vapor deposition SPIE proceedings $\mathbf{7 7 6 1} 77610 \mathrm{P}$

[28] Lebental B, Moujahid W, Lee C S, Maurice J-L and Cojocaru C S 2012 Graphene-based resistive humidity sensor for in-situ monitoring of drying shrinkage and intrinsic permeability in concrete. 4th Int. Symp. Nanotechnology in Construction (NICOM4),

[29] Baraton L, Gangloff L, Xavier S, Cojocaru C S, Huc V, Legagneux P, Lee Y H and Pribat D 2009 Growth of graphene films by plasma enhanced chemical vapour deposition Proceedings SPIE $739973990 \mathrm{~T}$

[30] Cojocaru C S, Senger A and Le Normand F 2006 A nucleation and growth model of verticallyoriented carbon nanofibers or nanotubes by plasma-enhanced catalytic chemical vapor deposition J. Nanosci. Nanotechnol. 6 1331-38

[31] Tanemura M, Iwata K, Takahashi K, Fujimoto Y, Okuyama F, Sugie H and Filip V 2001 Growth of aligned carbon nanotubes by plasma-enhanced chemical vapor deposition: Optimization of growth parameters J. Appl. Phys. 90 1529-33

[32] Meyyappan M and et al. 2003 Carbon nanotube growth by PECVD: a review Plasma Sources Sci. Technol. 12205

[33] Meyyappan M 2009 A review of plasma enhanced chemical vapour deposition of carbon nanotubes J. Phys. D-Appl. Phys. 42213001

[34] Peng Z, Yan Z, Sun Z and Tour J M 2011 Direct growth of bilayer graphene on SiO2 substrates by carbon diffusion through nickel ACS Nano 5 8241-47

[35] Cojocaru C S, Kim D, Pribat D and Bourée J-E 2006 Synthesis of multi-walled carbon nanotubes by combining hot-wire and dc plasma-enhanced chemical vapor deposition Thin Solid Films $\mathbf{5 0 1}$ 227-32

[36] Robertson J, Gerber J, Sattel S, Weiler M, Jung K and Ehrhardt H 1995 Mechanism of biasenhanced nucleation of diamond on Si Appl. Phys. Lett. 66 3287-89

[37] Cojocaru C S, Larijani M, Misra D S, Singh M K, Veis P and Le Normand F 2004 A new polarised hot filament chemical vapor deposition process for homogeneous diamond nucleation on Si(100) Diamond and Related Materials 13 270-76

[38] Stéphan O, Ajayan P M, Colliex C, Cyrot-Lackmann F and Sandré É 1996 Curvature-induced bonding changes in carbon nanotubes investigated by electron energy-loss spectrometry Phys. Rev. B 53 13824-29

[39] Nair R R, Blake P, Grigorenko A N, Novoselov K S, Booth T J, Stauber T, Peres N M R and Geim A K 2008 Fine structure constant defines visual transparency of graphene Science 320 1308-08

[40] Yong-Hui Z, Ya-Bin C, Kai-Ge Z, Cai-Hong L, Jing Z, Hao-Li Z and Yong P 2009 Improving gas sensing properties of graphene by introducing dopants and defects: a first-principles study Nanotechnology 20185504 
